\title{
Parental Emotion Socialization in Military Families
}

\author{
Yaliu He ${ }^{*} \quad$ Abigail Gewirtz Jodi Dworkin \\ University of Minnesota Twin Cities
}

\begin{abstract}
Reintegration after military deployment is a significant family stressor. Guided by Eisenberg's heuristic model of socialization of emotions, the present study examined the relationships between parental emotion socialization, children's emotionality and children's internalizing symptoms using a military sample. It was also investigated whether gender of parents and children impacted parental emotion socialization. Questionnaires were gathered from 248 families with a 4-12 year old child $(M=7.78)$ in which a parent had been deployed to Iraq or Afghanistan. Children's emotionality was positively correlated with children's internalizing symptoms and non-supportive parental emotion socialization. Independent-t-tests and two-way ANOVAs showed that mothers reported more supportive reactions towards children's negative emotions than fathers. Father reports of expressive encouragement were positively associated with child reports of anxiety and depression. Child gender did not influence how parents responded to negative emotions. Implications and future directions were discussed.
\end{abstract}

Keywords: deployment, emotionality, internalizing symptoms, parental emotion socialization

Since September 11, 2001, over 2 million children with active military duty parents in the United States have experienced one or more parental combat-related deployments during the ongoing conflicts of Operation Enduring Freedom (OEF) and Operation Iraqi Freedom (OIF). Military service members often experience combat exposure and potentially traumatic events during combat duty, which have been associated with physical, psychological and social challenges in transitioning from war to home, including injury, hyper-vigilance, mood swings, substance use and emotional withdrawal (MacDermid, 2006). Children in military families were found to be at high risk for displaying internalizing symptoms. Children

* Corresponding Author: Yaliu He, Doctoral Candidate Department of Family Social Science, University of Minnesota Twin Cities, 290 McNeal Hall, 1985 Buford Ave, St. Paul, MN, 55108 , USA.E-mail: hexxx268@umn.edu with a deployed parent reported higher rates of anxiety and stress disorders compared to nondeployed families (Chartrand, Frank, White, \& Shope, 2008; Gorman, Eide, \& Hisle-Gorman, 2010), and their distress level was positively related to the length of deployment (Chandra et al., 2010).

Due to combat exposure, deployed service members may demonstrate emotion communication deficits in their interactions with family members after returning home, such as limited self-disclosure and difficulties in identifying and expressing emotions (Gewirtz \& Davis, 2014; Price, Monson, Callahan, \& Rodriguez, 2006). Parental emotion socialization (PES) is defined as parenting practices that deal with children's emotions (e.g., how parents respond to and discuss children's emotions), which influence a child's learning regarding the experience, expression, and regulation of emotion and emotion-related behavior (Eisenberg, 
Cumberland, \& Spinrad, 1998; Eisenberg et al., 2001). Within military families, PES might be compromised due to impaired emotion communication, which negatively impacts children's adjustment. Therefore, PES might be essential in examining the trajectory of children's internalizing symptoms within military families, and the association of deployment status with PES should also be investigated. However, no study has examined PES using a military sample.

Emotionality is one of the core components of temperament and influences the direction of human development (Rothbart \& Bates, 2006). Emotionality refers to the individual differences in the amount and intensity of expressed negative or positive affect, fearfulness, irritability, ease of being soothed, and withdrawal from or attraction to novel situations (Propper \& Moore, 2006). Existing literature has shown that emotionality is related to parental emotion socialization and child internalizing symptoms (Oldehinkel, Hartman, Ferdinand, Verhulst, \& Ormel, 2007; Silk et al., 2011). Despite the stability over time obtained for measures of emotionality, studies have suggested that environmental factors lead to changes in child emotionality (Belsky, Fish, \& Isabella, 1991; Gottman et al., 1997). Indeed, Eisenberg et al. (1998) stated that parental socialization of emotions shapes and molds children's emotionality over time. Notably, Rothbart and Bates (2006) emphasized the importance of studying the mediation and moderation processes in the relationships between emotionality, parenting, and child outcomes. Therefore, it is crucial to examine the role of child emotionality in the relationships between parental emotion socialization and child internalizing symptoms. However, few researchers have done so.

This study utilizes a military sample from the baseline data of an intervention research project, known as After Deployment, Adaptive Parenting Tools (ADAPT). The primary goal is to understand the associations between parental emotion socialization, child emotionality and child internalizing symptoms, providing implications for future interventions focused on military families. Aims and hypotheses of the current study are as follows:

Aim 1: To understand the relationships among parental emotion socialization, child emotionality and child internalizing symptoms among military families.

Hypothesis 1-1: Non-supportive parental emotion socialization, child internalizing symptoms and child emotionality will be positively correlated with each other.

Hypothesis 1-2: Child emotionality will mediate the relationship between non-supportive parental emotion socialization and child internalizing symptoms (see Figure 1).

Aim 2: To examine how parents and children's gender influence parental emotion socialization. Given the previous mixed findings, no hypothesis regarding child gender was proposed.

Hypothesis 2: Mothers will report more supportive emotion socialization skills than fathers.

\section{Conceptual Framework: A Heuristic Model of the Socialization of Emotions}

Eisenberg and colleagues (Eisenberg et al., 1998, 1999, 2001; Spinrad et al., 2007) and Gottman and colleagues (Gottman, Katz, \& Hooven, 1996, 1997) have done extensive work in examining parental emotion socialization. There is no study that has studied parental emotion socialization within military families. However, deployed individuals' emotion regulation might be impaired and parental emotion socialization might be crucial for both parents' and children's emotion regulation capabilities.

Eisenberg and her colleagues (1998) developed a widely cited heuristic model of socialization of emotions. They contend that there are three aspects of PES: (1) parents' reactions to children's emotions; (2) parental discussion of emotions with children; and (3) parents' expression of emotions. Parents impact children's emotional development either directly through responses to children's emotions (the first and 
second aspects of PES; Hasting \& De, 2008) or indirectly through the emotional climate in the home (the third aspect of PES). For the purpose of this study, we focused on direct parental emotion socialization, the first and second aspects of PES.

Eisenberg and her colleagues categorized the first two aspects of PES into two types: supportive reactions and non-supportive reactions. Supportive reactions include expressive encouragement responses, emotionfocused responses and problem-focused responses. Non-supportive reactions consist of distress reactions, punitive responses and minimization responses (Fabes, Poulin, Eisenberg, \& Madden-Derdich, 2002).

According to the heuristic model, the implicit or explicit messages children receive from their parents regarding their negative emotions influence children's emotion regulation and expression (Eisenberg et al., 1998; Gottman et al., 1996). If parents consider their children's negative emotions as an opportunity for intimacy and teaching, they would not only respond warmly but also give direct instructions regarding emotion expression and experience (Gottman et al., 1997). Thus children would feel that their emotions are acceptable and worthy of expression and discussion (Gottman et al., 1997).

In contrast, if parents constantly deliver the message that negative emotions are undesirable and harmful through dismissive reactions (e.g., deny, punish or ignore) towards children's negative emotions, children gradually learn to hide and suppress their emotions. At the same time, they would also store the negative emotions and easily become highly aroused in a similar emotional situation because of previous repeated associations between discouragement and emotional expressivity (Eisenberg et al., 2001). Parents' non-supporting responses (dismiss, punitive, or minimize) to children's emotions directly interfere with children's regulatory physiology, emotion regulation abilities, social interactions with others and internal working model such as attachment style (Albrecht, Burleson, \& Goldsmith, 1994; Gottman et al., 1996, 1997).
The trajectory of developing internalizing problems involves efforts to control or suppress negative emotions (Zahn-Waxler, KlimesDougan, \& Slattery, 2000). As the heuristic model suggested, the dysregulated reactions of children caused by parents' dismissive responses to their negative emotions might lead to internalizing symptoms (Eisenberg, Fabes, \& Murphy, 1996; Eisenberg et al., 1998, 1999, 2001; Sanson, Hemphill, \& Smart, 2004). Indeed, a wealth of research has demonstrated that children whose parents were non-supportive (e.g., magnify, punish or neglect) appeared less socially competent (Denham, Mitchell-Copeland, Strandberg, Auerbach, \& Blair, 1997) and had more internalizing problems (Hastings \& De, 2008; O’Neal \& Magai, 2005; Silk et al., 2011; Suveg, Zeman, Flannery-Schroeder, \& Cassano, 2005) than children whose parents were supportive. This model is particularly relevant to military families because returning service members' experiential avoidance (e.g., trying to suppress a thought to avoid fear) might prevent them from expressing emotions, which interferes with parental emotion socialization and discourages children's emotion expression.

\section{Literature Review}

\section{Emotionality and Internalizing Symptoms}

Diener, Larsen, Levine, and Emmons (1985) suggested that there were two dimensions of emotionality: intensity and frequency. The current study focused on the intensity of child emotionality, including the intensity of general emotionality, negative emotionality and positive emotionality.

It is not surprising that negative emotionality has been found to be positively related to internalizing symptoms among children and adolescents (Eisenberg et al., 2001; Oldehinkel et al., 2007; Sanson et al., 2004; Zahn-Waxler et al., 2000). In particular, sadness, anxiety, fear, and distress in response to specific stimuli (e.g. novel situations) were believed to predict internalizing symptoms (Keltner, Moffitt, \& 
Stouthamer-Loeber, 1995). Indeed, Eisenberg et al. (1998) argued that individuals who were unable to regulate the intensity of their emotions were more likely to become physiologically over-aroused and exhibit unregulated behaviors.

Although positive emotions are often considered adaptive (Eisenberg, Wentzel, \& Harris, 1998; Lengua, 2003), some studies showed that the intensity of positive emotionality was related to low regulation and sometimes led to negative social outcomes (e.g., Oldehinkel, Hartman, De Winter, Veenstra, \& Ormel, 2004; Rothbart, Ahadi, Hershey, \& Fish, 2001; Rydell, Berlin, \& Bohlin, 2003; Sallquist et al., 2009). For instance, Rothbart et al. (2001) indicated that the high intensity of pleasure children display was positively associated with their high impulsiveness and activeness. In a six-year longitudinal study that tracked children from kindergarten, children who had high intensity positive, negative emotionality and general emotionality, as reported by parents and teachers, had a sharp decline in social competence across time (Sallquist et al., 2009). The present study tested the relationship between child emotionality and child internalizing behaviors (see Hypothesis 1-1).

\section{Parental Emotion Socialization, Child Emotionality and Child Internalizing Symptoms}

Toth and Cicchetti (1996) proposed that developmental trajectories for children were both the producer and the product of the exchanges with the environment. Although emotionality is usually considered part of one's biological makeup and moderately stable over time (Zeanah \& Fox, 2004), there is also substantial evidence for the role of environmental factors (e.g., parental emotion socialization) in modifying the expression of emotion (Fox \& Calkins, 2003; Rothbart \& Bates, 2006; ZahnWaxler et al., 2000).

In fact, the heuristic model of socialization of emotions (Eisenberg et al., 1998) suggests that negative parental responses encouraged more negative emotions and behaviors in children. This theoretical hypothesis was supported by
Eisenberg et al. (1999). They found that mothers' reported punitive reactions at age 6 to 8 predicted mothers' reports of children's temperament at age 8 to 10 . They also found that parental report of distressed reactions to child's negative emotions was positively related to children's negative emotionality concurrently and across time. Other studies also supported this assumption that children with high levels of negative emotionality might be vulnerable to the impact of negative parenting (Belsky, Hsieh, \& Crnic, 1998; Paulussen-Hoogeboom, Stams, Hermanns, \& Peetsma, 2007; Sanson et al., 2004). Thus, in our study we hypothesized nonsupportive parental emotion socialization was positively related to child emotionality (see Hypothesis 1-1).

In the heuristic model, Eisenberg et al. (1998) proposed that the relationship between emotionrelated parenting practices and child outcome behaviors was mediated by child's arousal level. Given that negative emotionality was positively associated with physiological arousal and the finding that there is a direct link between negative emotionality and internalizing symptoms (Eisenberg et al., 1998), it is likely that children's negative emotionality will increase if their parents exhibit non-supportive emotion socialization skills, which leads to more child internalizing symptoms. Therefore, parental socialization of emotions was predicted to be associated with child internalizing symptoms through the mediation of child emotionality (see Hypothesis 1-2).

\section{Gender and Parental Emotion Socialization}

Most research on parental emotion socialization has focused exclusively on mothers. A few studies suggested that fathers may play a less important role in engaging with children's emotions than mothers (Baker, Fenning, \& Crnic, 2011; Fivush, Brotman, Buckner, \& Goodman, 2000; Garside \& Klimes-Dougan, 2002; Gottman et al., 1996; Hastings, Rubin, \& DeRose, 2005). However, fathers were known to make a unique contribution to children's social development (Parke, 1995), thus it is important to understand how emotion socialization differs by parents' 
gender. Given most of the fathers and some of the mothers in the sample were deployed, it is crucial to understand how deployment experiences impact their socialization of their children's emotions.

Hastings and De (2008) indicated that fathers and mothers responded differently to children's emotions. They found paternal responses to children's anger and maternal reactions to children's sadness were associated with children's internalizing symptoms. Fathers reported more punitive reactions and less supportive responses to child negative emotions than mothers (Eisenberg et al., 1996; Engle \& McElwain, 2011; McElwain, Halberstadt, \& Volling, 2007). For the current study, we examined the role of parents' gender in parental emotion socialization (see Hypothesis 2).

Research that examined the influence of children's gender on parental emotion socialization tends to be mixed. Eisenberg et al. (1998) theoretically suggested that fathers and mothers might respond to children's negative emotions differently based on children's gender. Fathers were found to reward girls whereas punish boys for showing sadness and fear because those emotions were stereotypically considered feminine traits (Birnbaum \& Croll, 1984; Garside \& Klimes-Dougan, 2002). Parents were more accepting of anger in boys than in girls (Birnbaum \& Croll, 1984). Moreover, Engle and McElwain (2011) found that fathers had more minimization reactions towards girls than mothers. However, other studies failed to reveal patterns of child gender in parents' reports of reactions (Eisenberg et al., 1999; Fabes, Leonard, Kupanoff, \& Martin, 2001). To explore how parental emotion socialization relates to child gender, the current study tested if maternal and paternal emotion socializations varied based on child gender.

\section{Method}

\section{Procedures}

The recruitment team ADAPT made extensive outreach efforts to recruit participants. They built connections with the Minnesota local Army, Air National Guard, and local Reserve units. They presented the study at mandatory pre-deployment events, sent flyers through Minneapolis Veterans Affairs Medical Center to all veterans, posted flyers in the Twin Cities area, published in media (e.g., newspaper, Facebook and Twitter), and built a reputation through word of mouth by military parents.

For inclusion in the ADAPT study, families had to have at least one child between the ages of four and twelve living with them, at least one parent who had been deployed to Iraq or Afghanistan, and have high -speed internet access at home. Eligible parents could either sign up for the study by themselves right away or leave information for project staff to contact them. Parents were also asked if they were willing to participate in a weekly parenting group in the Twin Cities metro area.

Eligible parents were invited to participate in the study and directed to the consent form on the Internet. Next, they received an email with a link to fill out the online survey. Parents' reports of their own and their children's demographic information, and parents' reports of child emotionality were collected in the online assessment. Subsequently, project staff contacted parents to schedule an in-home assessment. Parents' report of parental emotion socialization and children's report of their internalizing symptoms were gathered at in-home assessments. Children and parents were assessed in separate rooms. Children were given incentives such as snacks and a toy for finishing the assessment. They had the choices for quitting the assessment and having breaks during the assessment. Each parent was paid $\$ 25$ for the online survey and each family was paid $\$ 50$ for finishing the inhome assessment.

\section{Participants}

The final sample for ADAPT was 336 families. By fall 2013 when the data were collected for the current study, 279 families had finished both the online and in-home 
assessments. This study should therefore be considered preliminary as it does not include data from the full baseline sample. Moreover, 38 out of the 176 items in Child Self-Report Personality-Adolescent version (SRP-A; assessing children from 12 to 18 years) were missing due to manual error, which largely influenced the validity of the subscales of interest. Therefore, 30 families with children 12 years of age were dropped from the study sample. One same-sex couple was also dropped. As a result, 248 families constituted the sample for this study, including 438 parents (227 mothers and 202 fathers, 9 parents' gender was missing) and 438 children (189 boys and 238 girls, 11 children's gender was missing). Each family consisted of a parent and a child, or two parents and a child. Household income ranged from less than $\$ 10,000$ to more than $\$ 155,000$ per year. Nearly three-quarters $(73.2 \%)$ of the parents reported that their annual household income was above $\$ 50,000$.

The sample primarily consisted of middleclass White European American parents. The racial composition of the parents was $91.3 \%$ European American, 2.5\% African American, 2.1\% Asian American, 0.2\% Native American, $2.5 \%$ multiracial, and $1.4 \%$ unreported. Parents reported their ethnic background as $93.6 \%$ nonHispanic, 3.4\% Hispanic and 2\% unknown. This racial and ethnic distribution is similar to statewide data (87\% European American). More than half of parents $(51.5 \%)$ reported having at least a Bachelor's degree. Nearly all $(89.7 \%)$ participants were married. Ninety percent of fathers reported that they had ever been deployed to Iraq or Afghanistan but only $24.8 \%$ mothers reported that they had been deployed.

The mean age of children was 7.78 years $(S D$ $=2.19$ ), ranging from 4.06 years to 11.97 years old. Twenty-eight children's age was missing. Children were mostly European American (86.5\%); a few were multiracial (8.2\%), African American (2.1\%), Asian American (1.4\%) and Native American (0.5\%). Six parents' responses of children's races were missing. Parents reported their children's ethnic background as
88.4\% non-Hispanic and 8.9\% Hispanic. Eleven parents preferred not to answer or indicated that they did not know their children's ethnic background; one parent's report of children's ethnic background was missing.

\section{Measures}

The measures this study included are: demographics, parental emotion socialization (CCNES), child emotionality (QMOMEI), and child's internalizing symptoms (BASC-2-SRP).

Demographics. Parents reported their gender, education level, race, ethnicity, deployment status, marital status and annual household income. They also provided their children's gender, race, ethnicity and date of birth.

Parental Emotion Socialization. Parental emotion socialization was assessed with the Coping with Children's Negative Emotions Scale (CCNES; Eisenberg \& Fabes, 1994; Fabes, Eisenberg, \& Bernzweig, 1990). The validity of this measure is suggested by its relationship with children's social and emotional competence (Eisenberg \& Fabes, 1994; Eisenberg, Fabes, \& Murphy, 1996). The measure presents parents with 12 scenarios describing occasions of their child experiencing negative emotions, especially upset and anger (Fabes, Eisenberg, \& Bernzweig, 1990). For each scenario, parents were asked to identify how likely they would be to respond in each of six different ways on a 7-point scale from very unlikely to very likely (Fabes et al., 1990). Corresponding to the six different ways parents might respond, six subscales of CCNES were developed by computing a mean of the 12 items in each subscale.

(1) Parental distress reactions (DR), referring to the degree to which parents experience distress when children express negative affect (e.g., "get angry at my child"; "remain calm and not let myself get anxious" [reverse coded]; $\alpha$ $=.60$ for mothers and $\alpha=.72$ for fathers); (2) punitive responses $(P R)$, reflecting the degree to which parents respond with punitive reactions that decrease their exposure to or need to deal 
with the negative emotions of their children (e.g., "send my child to his or her room to cool off"; "tell my child to stop crying or he or she won't be allowed to ride his or her bike anytime soon"; $\alpha=.69$ for mothers and $\alpha=.80$ for fathers ); (3) minimization responses (MR), indicating the degree to which parents minimize the seriousness of the situation or devalue the child's problem or distressful reaction (e.g., "tell my child that he or she is over-reacting" "tell my child to quit over-reacting and being a baby"; $\alpha$ $=.79$ for mothers and $\alpha=.82$ for fathers); (4) expressive encouragement responses (EE), defining the degree to which parents encourage children to express negative affect or the degree to which they validate child's negative emotional states (e.g., "encourage my child to talk about his or her nervous feelings" "encourage my child to talk about his/her feelings of embarrassment"; $\alpha$ $=.87$ for mothers and $\alpha=.87$ for fathers); (5) emotion-focused responses (EFR), showing the degree to which parents respond with strategies that are designed to help the child feel better (e.g., "comfort my child and try to get him or her to forget about the accident" "suggest that my child think about something relaxing so that his or her nervousness will go away"; $\alpha=.79$ for mothers and $\alpha=.81$ for fathers); (6) problem-focused responses (PFR), indicating the degree to which parents help the child solve the problem that caused the child's stress (e.g., "help my child think of constructive things to do when other children tease him/her" "tell my child that I'll help him/her practice so that he/she can do better next time"; $\alpha=.75$ for mothers and $\alpha=.79$ for fathers; Fabes et al., 1990).

The first three subscales (DR, PR and MR) were considered non-supportive responses and the remaining three subscales (EE, EFR and PFR) were regarded as supportive parental reactions to child negative emotions (Fabes et al., 2002). CCNES has been tested and showed good internal reliability, test-retest reliability and construct validity (Eisenberg et al., 1996; Fabes et al., 2002).

Child Emotionality. Children's emotionality was assessed with an adapted version of Larsen and Diener's (1987) Affect Intensity Scale (Eisenberg et al., 1993, 1995, 1996). It focused on the intensity rather than the frequency of emotionality (Sallquist et al., 2009). There are three dimensions to this measure, including intensity of general emotions (GEI), intensity of negative emotions (NEI) and intensity of positive emotions (PEI). Parents responded using a 7 -point scale $(1=$ never to $7=$ always $)$. The adaptive Affect Intensity Scale showed good internal consistency and test-retest reliability (Eisenberg et al., 1993, 1995, 1996). Parents rated children's GEI (e.g., "When my child feels an emotion, either positive or negative, he/she feels it strongly;" $\alpha=.83$ for mothers and .76 for fathers) using seven items. Parents reported children's PEI (e.g., "When my child is happy, it is like he/she is bursting with joy;" $\alpha=.82$ for mothers and .78 for fathers) using six items and children's NEI (e.g., "When my child experiences anxiety, it normally is very strong;" $\alpha=.72$ for mothers and .76 for fathers) using five items.

Child Internalizing Symptoms. Child internalizing symptoms were assessed using scales from the Behavior Assessment System for Children (2nd Ed.) - Child Self-Report Personality (BASC-2-SRP; Reynolds \& Kamphaus, 1998). The BASC-2 is a widely-administered, multidimensional system used to assess broad domains of externalizing problems, internalizing problems, and adaptive skills of children and adolescents. It has demonstrated adequate internal consistency, test-retest reliability, and validity (Reynolds \& Kamphaus, 1998). Given the developmental stage, children's self-report measure of internalizing symptoms varies regarding both of the format and content. Children who are younger than 8 years were given an oral interview ( 65 items) by assessment staff while children who are 8 years or older fill out a survey (139 items) by themselves. Considering the age range of the children (four to twelve years) in the study, two scales of the SRP were applied separately to children depending on their age: preschooler (SRP-I, 65 items) and children (SRP-C, 139 items). Given 
that the number of items and options of the preschooler version and children version are different, raw scores were transformed into standardized scores ( $Z$ scores) to make them comparable.

Identified subscales of interest for the current study include the following: the primary Scales of Depression, Anxiety and Social Stress. Specifically, The Depression Scale assesses traditional symptoms of depression, including feelings of loneliness, sadness, and inability to enjoy life $(\alpha=.78$ for preschooler and .79 for older children). The Anxiety Scale is defined as feelings of nervousness, worry, and fear that are typically irrational and poorly defined in the mind of the individual; the tendency to be overwhelmed by problems $(\alpha=.81$ for preschooler and .88 for older children). The Social Stress Scale measures the level of stress experienced by children in relation to their interactions with peers and others $(\alpha=.76$ for preschooler and .84 for older children). It is likely to be pervasive and chronic rather than acute and transient.

\section{Analytic Strategy}

Missing Values Analysis. The percentage of missing data is small in the study sample. In addition to demographics as reported in the participant section, 19 responses were missing for child emotionality (QMOMEI). Seven responses were missing for BASC-SRP. However, for CCNES, one scenario out of twelve was missing due to manual error. Given that the six responses from that scenario contributed to the computation of the six subscales of CCNES, the Missing Value Analysis (MVA) module of SPSS was used to impute missing data of the CCNES scenario. The MVA module investigates missing data patterns and imputes missing values through a maximum likelihood method based on expectation-maximization algorithms (Little \& Rubin, 1987). This random residual imputation process was run for 50 iterations in order to minimize the differences between covariance matrices. The variance $\mathrm{t}$-test and cross tabulation of categorical variables table, revealed no significant differences between respondents and non-respondents.

Analysis Methods. First, correlation analyses were conducted to investigate if child internalizing symptoms were related to parental emotion socialization and child emotionality in both mother-child dyads and father-child dyads. If the correlation is significant, multiple regressions would be used to test whether child emotionality mediates the relationship between parental emotion socialization and children's internalizing symptoms.

Last, a series of independent-samples t-tests and two-way ANOVAs were conducted to test how the gender of parents and children was associated with parental emotion socialization.

\section{Results}

\section{Preliminary Analyses}

First, we tested whether demographic variables including child age and gender, parental education, parental deployment history and family income were associated with internalizing symptoms in both mother-child dyads and father-child dyads. For mother-child dyads, children's age was negatively associated with their social stress and depressive symptoms, $r(225)=-.16$ and $-.15, p<.05$ and .05 . No other significant associations were found in motherchild dyads and no significant associations were found in father-child dyads. Thus, these demographic variables except children's age were not considered further. For descriptive purposes, Table 1 and Table 2 present means and standard deviations for the study measures for mother-child dyads and father-child dyads by child gender, respectively. Tables 3 and 4 present inter-correlations among the study measures for mother-child dyads and father-child dyads, respectively. 
Table 1

Descriptive Statistics for Study Measures (Mother-Child Dyads)

\begin{tabular}{lcccccc}
\hline \multirow{2}{*}{ Measure } & \multicolumn{2}{c}{ Total $(n=227)$} & \multicolumn{2}{c}{ Boys $(n=101)$} & \multicolumn{2}{c}{ Girls $(n=125)$} \\
\cline { 2 - 6 } & Mean & $S D$ & Mean & $S D$ & Mean & $S D$ \\
\hline Maternal Reports (n=227) & & & & & & \\
Distress Reactions & 2.77 & 0.69 & 2.71 & 0.70 & 2.80 & 0.68 \\
Punitive Reactions & 2.39 & 0.64 & 2.40 & 0.66 & 2.38 & 0.63 \\
Minimization Reactions & 2.53 & 0.81 & 2.45 & 0.87 & 2.59 & 0.75 \\
Encouragement Reactions & 5.18 & 0.93 & 5.20 & 0.97 & 5.17 & 0.90 \\
Emotion-focused Reactions & 5.67 & 0.78 & 5.62 & 0.85 & 5.70 & 0.72 \\
Problem-focused Reactions & 5.93 & 0.64 & 5.93 & 0.67 & 5.93 & 0.61 \\
General Emotionality & 4.63 & 0.99 & 4.63 & 0.98 & 4.62 & 1.00 \\
Positive Emotionality & 4.90 & 0.95 & 4.76 & 1.06 & 5.00 & 0.84 \\
Negative Emotionality & 4.49 & 1.01 & 4.57 & 1.04 & 4.41 & 0.99 \\
Child Reports & & & & & & \\
Depression & 0.01 & 0.99 & 0.09 & 0.94 & -0.07 & 1.01 \\
Anxiety & 0.02 & 0.99 & 0.01 & 0.99 & 0.03 & 0.99 \\
Social Stress & 0.02 & 1.00 & 0.09 & 1.04 & -0.05 & 0.97 \\
\hline
\end{tabular}

Note. One child's gender was missing.

Table 2

Descriptive Statistics for Study Measures (Father-Child Dyads)

\begin{tabular}{lcccccc}
\hline \multirow{2}{*}{ Measure } & \multicolumn{2}{c}{ Total $(n=202)$} & \multicolumn{2}{c}{ Boys $(n=88)$} & \multicolumn{2}{c}{ Girls $(n=113)$} \\
\cline { 2 - 7 } & Mean & $S D$ & Mean & $S D$ & Mean & $S D$ \\
\hline Paternal Reports(n=202) & & & & & & \\
Distress Reactions & 2.84 & 0.79 & 2.80 & 0.77 & 2.87 & 0.81 \\
Punitive Reactions & 2.70 & 0.83 & 2.75 & 0.86 & 2.68 & 0.80 \\
Minimization Reactions & 3.08 & 0.82 & 3.05 & 0.84 & 3.11 & 0.81 \\
Encouragement Reactions & 4.54 & 0.99 & 4.66 & 0.93 & 4.44 & 1.02 \\
Emotion-focused Reactions & 5.36 & 0.80 & 5.41 & 0.79 & 5.32 & 0.81 \\
Problem-focused Reactions & 5.57 & 0.73 & 5.58 & 0.72 & 5.56 & 0.75 \\
General Emotionality & 4.65 & 0.88 & 4.68 & 0.90 & 4.70 & 0.86 \\
Positive Emotionality & 4.96 & 0.80 & 4.94 & 0.80 & 4.94 & 0.87 \\
Negative Emotionality & 4.40 & 1.02 & 4.44 & 1.06 & 4.47 & 1.00 \\
Child Reports & & & & & & \\
Depression & 0.00 & 0.98 & 0.09 & 0.94 & -0.09 & 0.99 \\
Anxiety & 0.02 & 0.97 & 0.01 & 0.99 & 0.00 & 0.98 \\
Social Stress & 0.05 & 1.00 & 0.09 & 1.04 & -0.03 & 0.98 \\
\hline
\end{tabular}

Note. One child's gender was missing. 
He, Gewirtz, \& Dworkin

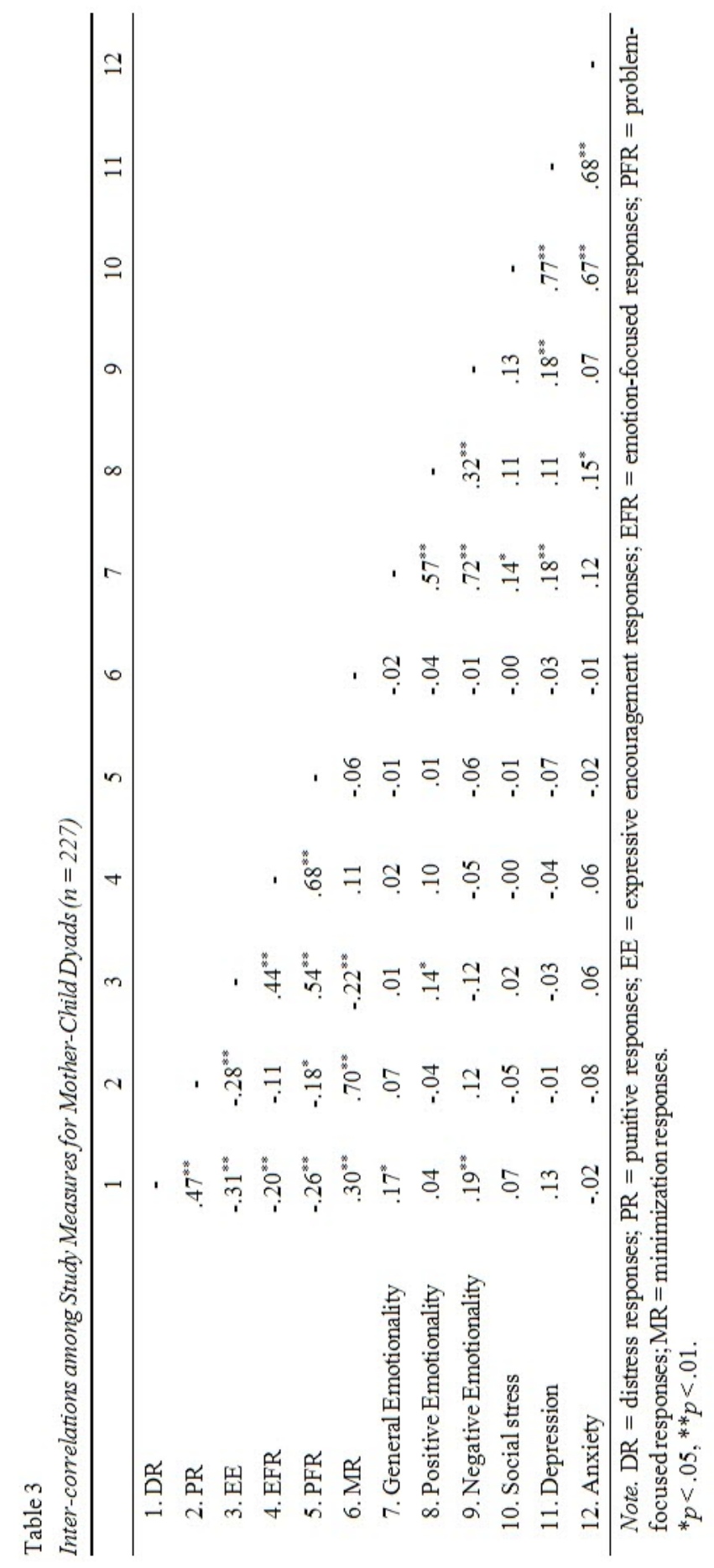




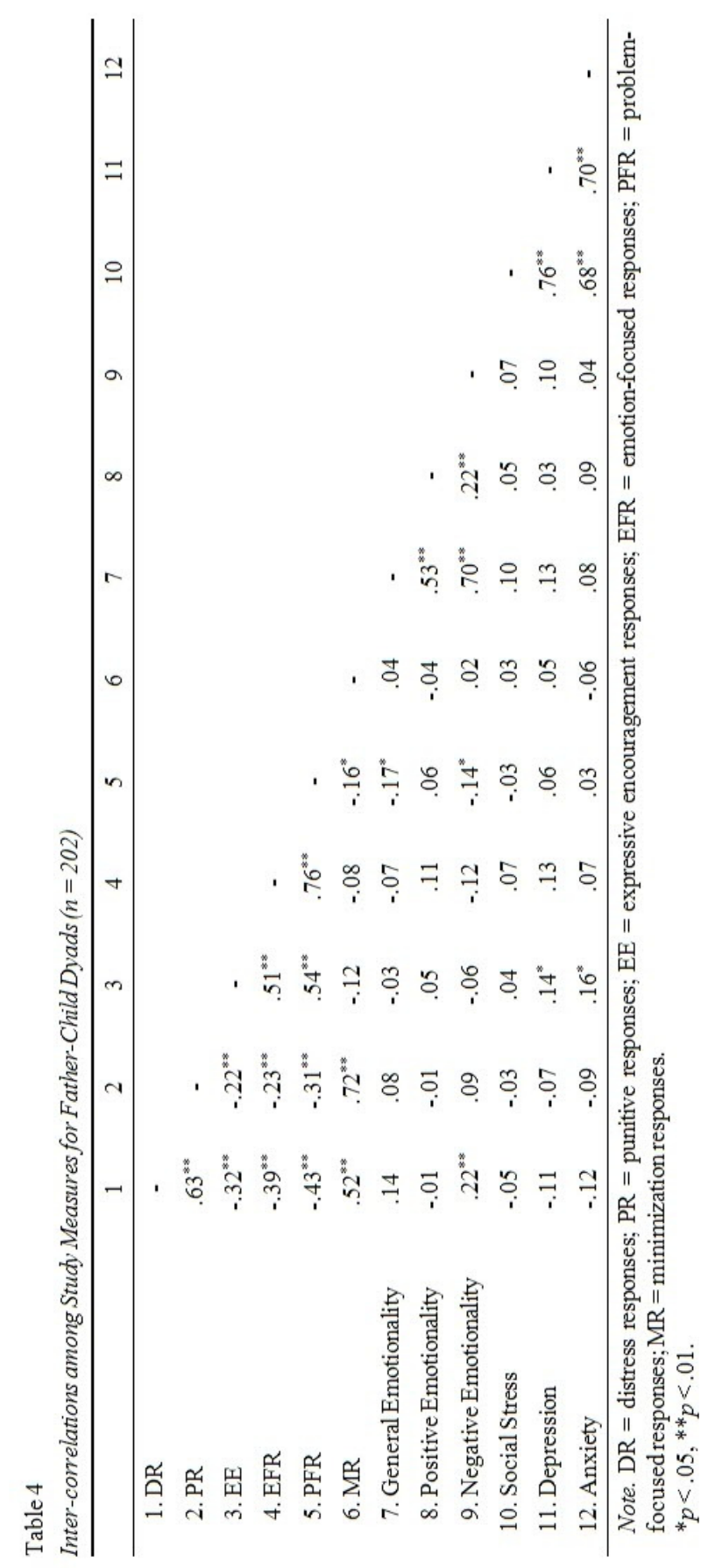

Child Studies in Asia-Pacific Contexts, 2015, 5(1) 


\section{Correlation Analyses}

Correlational analyses were conducted to examine the relationships among parental emotion socialization, children's emotionality and child internalizing symptoms in both mother-child and father-child dyads (see Tables 3 and 4).

The results of the correlations revealed no significant association between mothers' reactions to child negative emotions and child internalizing symptoms. Only mothers' distress reactions to child negative emotions were found to approach significance in its association with children's depressive symptoms, $r(225)$ $=.13, p=.06$. Interestingly, fathers' expressive encouragement was positively related to child anxiety and depression, $\mathrm{r}(200)=.16$ and $.14, p$ $<.05$ and $p<.05$, respectively.

Results showed that emotionality was positively associated with internalizing symptoms only for mother-child self-reports, not fatherchild self-reports. For mother-child dyads, results indicated that child positive emotionality was positively associated with anxiety symptoms, $r(225)=.15, p<.05$. Child general emotionality was positively related to social stress and depressive symptoms, $r(225)=.14, .18$, and $p$ $<.05, .01$, respectively. For father-child dyads, no significant correlation between child emotionality and internalizing symptoms was found.

Results also suggested child general emotionality and negative emotionality were positively linked to mothers' distress reactions, $r(225)=.17$ and $.19, p<.05$ and .01 , respectively. We found similar results in paternal reports. Fathers' distress reactions were positively related to child negative emotionality, $r(200)=.22, p<.01$. However, we did not find any correlation between child emotionality and the other five dimensions of maternal emotion socialization and paternal emotion socialization.

Hypothesis 1-1 was partially supported. Child emotionality was positively related to mothers' non-supportive emotion socialization (a path) and child internalizing symptoms (b path). Fathers' supportive emotion socialization was positively related to child internalizing symptoms (c path). Fathers' non-supportive emotion socialization was positively related to child emotionality (a path). However, because one of the main effects (c path for mothers and b path for fathers) was not significant for motherchild dyads and father-child dyads respectively, multiple regression analyses were not conducted to assess each component of the proposed mediation model. Therefore, Hypothesis 1-2 was not supported.

\section{Independent-samples T-Tests and Two-Way ANOVA}

To determine whether parent-reported reactions to child negative emotions differ by parent gender, a series of independent-samples t-tests were conducted at the subscale level, for a total of six analyses (i.e., one for each of the six subscales of CCNES). Given that multiple comparison analyses easily cause inflated Type I errors, a Bonferroni-correction was utilized by dividing the desired alpha-level (.05) by the number of tests (six), yielding a corrected alpha level of .008 . Using this stricter criterion ( $p$ $<.008)$, results revealed five significant effects for parents' gender by comparing fathers' and mothers' reports of emotion socialization. There was a significant difference in Punitive Reactions between fathers $(M=2.73, S D=0.83)$ and mothers $(M=2.42, S D=0.66), t(427)=$ $4.30, p<.001$; in Minimized Reactions between fathers $(M=3.10, S D=0.85)$ and mothers $(M=$ $2.56, S D=0.80), t(427)=6.79, p<.001$; in Encouragement Expressive Reactions between fathers $(M=4.53, S D=0.97)$ and mothers $(M=$ 5.17, $S D=0.93), \mathrm{t}(427)=-6.94, p<.001$; in Emotion Focused Reactions between fathers $(M$ $=5.34, S D=0.81)$ and mothers $(M=5.66, S D=$ $0.78), t(427)=-4.08, p<.001$; and in Problem Focused Reactions between fathers $(M=5.54$, $S D=0.74)$ and mothers $(M=5.91, S D=0.65)$, $t(427)=-5.43, p<.001$.

According to the results of t-tests, parents' gender might contribute to parental responses to child negative emotions. However, parents' previous deployment status might be a 
confounding factor in examining the gender differences in PES. Because most fathers were deployed, in order to exclude the possibility that it is parents' deployment instead of gender that impacts their emotion socialization, two steps with several follow-up analyses were implemented.

In the first step, a series of two-way ANOVAs tested mothers and fathers responses to child negative emotions by deployment status. After a Bonferroni-correction was applied, the corrected alpha level was .008 (.05/6). For parents' punitive reactions, the main effects of deployment experiences and parents' gender and the interaction between them were not significant based on the criterion of $\alpha=.008$. For parents' expressive encouragement responses, the main effect of parents' gender was statistically significant but the main effect of deployment status was not significant. Mothers reported significantly higher levels of encouragement reactions to child negative emotions than fathers, $F(1,427)=29.22, p$ $<.001$. However, the interaction between parents' gender and deployment experiences were non-significant. Parents' emotion-focused responses, problem-focused responses and minimization responses, yielded similar results as for parents' expressive encouragement. Only the main effect of parents' gender was significant $F(1,427)=14.98, p<.001 ; F(1,427)$ $=19.76, p<.001 ; F(1,427)=18.87, p<.001$, respectively. Table 5 presents the means and standard deviations for the main effect.

In the second step, a series of independentsamples t-tests were conducted to examine if there was a difference in maternal emotion socialization between civilian mothers $(n=170)$ and deployed mothers $(n=56)$. Results showed no significant difference between civilian mothers and deployed mothers in all the six subscales of parental responses to child negative emotions.

Follow-up analysis suggested that parental responses to child negative emotions may vary by parent gender instead of deployment history. Fathers reported more minimization actions and punitive actions towards child negative emotions than mothers. Compared to fathers, mothers reported more supportive reactions (encouragement expressive reactions, emotionfocused reactions and problem-focused reactions) to child negative emotions. These results supported Hypothesis 2.

To test if parents' report of emotion socialization differs by child's gender, six independent samples t-tests were computed in mother-child and father-child reports (with the Bonferroni correction). With the more stringent $p$-value of .008 , there were no significant differences in either fathers' or mothers' reports of emotion socialization between sons and daughters.

Table 5

Main Effects in the Two-Way ANOVA: Differences in Parental Emotion Socialization by Parent Gender

\begin{tabular}{|c|c|c|c|}
\hline \multirow{2}{*}{ Parental Emotion Socialization } & Mothers & Fathers & \multirow{2}{*}{$F$} \\
\hline & $M(S D)$ & $M(S D)$ & \\
\hline Distress Responses & $2.79(0.70)$ & $2.87(0.81)$ & 5.20 \\
\hline Punitive Responses & $2.42(0.66)$ & $2.73(0.83)$ & $9.00^{*}$ \\
\hline Minimization Responses & $2.56(0.80)$ & $3.10(0.85)$ & $1.33^{*}$ \\
\hline Expressive Encouragement & $5.17(0.93)$ & $4.53(0.97)$ & $0.04 *$ \\
\hline Emotion-focused Responses & $5.65(0.78)$ & $5.34(0.81)$ & $0.26^{*}$ \\
\hline Problem-focused Responses & $5.91(0.65)$ & $5.54(0.74)$ & $5.76^{*}$ \\
\hline
\end{tabular}

Note. Response options for parental emotion socialization from $1=$ very unlikely to $7=$ very likely.

$* p<.008$ 


\section{Discussion}

Reintegration after military deployment is an exceptional family stressor, often associated with difficulties in emotions. The current study is the first to investigate parental emotion socialization in military families. The current conflict is particularly well suited for understanding these relationships, families faced long, repeated, frequent deployments with short breaks between them (Hosek, Kavanagh, \& Miller, 2006).

It was found that mothers' responses to child negative emotions were not related to child internalizing symptoms. However, fathers' expressive encouragement was positively related to child anxiety and depression. Emotionality was positively associated with internalizing symptoms in mother-child dyads but not fatherchild dyads. Child general emotionality and negative emotionality were positively related to parental distress reactions.

The association between mothers' distress responses to child negative emotions and child depressive symptoms was approaching significance; maternal distress responses were significantly positively related to child negative emotionality. Therefore, it is possible that maternal distress reactions might contribute more to intensifying child negative emotionality and triggering child depression compared with the other two non-supportive reactions (punitive reactions and minimization reactions). In addition, given that minimization and punishment are more behavior-oriented, they may not directly exacerbate children's negative emotionality or raise their physiological arousal level. On the contrary, distress reactions can be considered more emotional reactions. Fabes et al. (2002) demonstrated that parental distress reactions were positively correlated with their personal distress and anger. We posited that children might be vulnerable to maternal emotional stress, which is consistent with previous findings (Eisenberg \& Fabes, 1994).

In mother-child dyads, child positively emotionality and general emotionality were positive related to anxiety, and social stress and depression, respectively. Given the measurement for emotionality in the current study focused on assessing the intensity of emotionality, those results were consistent with previous findings that the intensity of positive emotionality was related to negative outcomes (e.g., Rydell et al., 2003; Sallquist et al., 2009).

In father-child dyads, it is interesting that fathers' expressive encouragement was positively linked to child anxiety and depression, the opposite direction than expected. Children learn emotions through both parents' direct responses to their emotions and their indirect observation of parents' expression of emotions. Because most fathers were deployed, it is likely that fathers' deployment experiences increased their avoidant coping strategies (which are core to posttraumatic stress symptoms), which led to their limited expression of emotions in the family. Fathers may send mixed messages to children by encouraging children's expression of negative feelings at the same time they are withdrawing their own negative emotions. Children may mimic fathers' avoidant reactions to emotions, and thus may interpret their own negative feelings as a weakness and tend to suppress those feelings when fathers' show expressive encouragement. This potentially contributes to child depression and anxiety symptoms. Our results suggest that supportive parental responses to children's negative emotions might not always be related to positive child outcomes; indirect parental emotion socialization, namely parents' emotion expression, and the context, such as individuals' past traumatic experiences, might also be a factor. Further investigation needs to be conducted.

The current study is also the first to examine the indirect effect of child emotionality on the relationship between parental emotion socialization and child internalizing symptoms. The mediating effect was not prominent in the mother-child dyads or the father-child dyads due to lack of significant findings on one of the main effects (Figure 1; c path for mothers and b path for fathers). However, c path for mothers was approaching significance. A larger sample size may allow for detecting the mediation. In addition, the skewed distribution of the three 


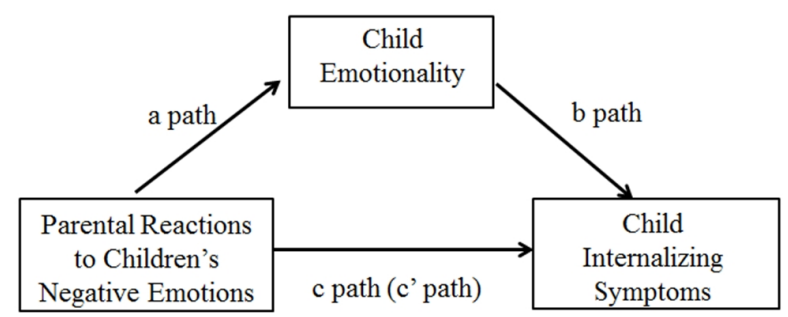

Figure 1. Mediation model of the indirect effect of parental reactions to child negative emotions on child internalizing symptoms through child emotionality.

a path $=$ direct effects of IV on mediator, $\mathrm{b}$ path $=$ direct effect of mediator on DV, $\mathrm{c}$ path $=$ total effect of IV on DV, c' path = direct effect of IV on DV.

scales assessing social stress, depression and anxiety, suggesting a lack of variation of the dependent variables, may partially explain the lack of significant findings. Furthermore, although at least one parent has participated in combat, according to preliminary results, their distress level was not very high. This indicates that the family's functioning might be compromised by one parent's deployment, but it may also be protected by demographic factors (e.g., high household income, high education level, and marital relationship) and other environmental factors. The protective factors that buffer the combat stress need further investigation.

As suggested by the results of independent $t$ tests and two-way ANOVAs, parents' deployment history had no interaction with parents' gender in terms of contributing to their responses to child negative emotions. Furthermore, there was no significant difference between civilian mothers and deployed mothers regarding their emotion socialization.

There was also no significant child gender difference found in the subscales of the CCNES in either fathers' or mothers' reports; fathers and mothers' responses to child negative emotions did not vary by child gender. This finding is consistent with previous research on child gender (Eisenberg et al., 1999; Fabes et al., 2002, Fabes et al., 2001).

\section{Strengths, Limitations and Future Directions}

The present study builds upon existing research and theories in important ways and has a number of strengths. No previous study examined parental emotion socialization in military families. The sample also included both mothers and fathers, which provided the chance to examine fathers' emotion socialization and compare mothers and fathers. Although the mediating effect of child emotionality on the relationships between parental emotion socialization and child internalizing symptoms was not found, the positive association between paternal supportive emotion socialization and child internalizing symptoms suggests some unique characteristics of military sample.

However, these findings should be considered as preliminary and interpreted with caution due to several design and measurement limitations. Cross-sectional designs do not suggest the direction of the correlation results. For future studies, longitudinal designs are needed. The measures in the study were all self-reports. As a future direction, it is important to consider utilizing multiple methods of measurement, such as observational measures to assess parental emotion socialization. The measurement of the indirect approach of parental emotion socialization (i.e., parents' expression of emotions) should also be included. It would also be helpful to ask teachers to report child internalizing symptoms. Moreover, the study did not conduct family-level analyses dealing with nested data. As children develop within a family system, it would be interesting to examine the concordance in parental emotion socialization between parents and how it impacts child 
outcomes (Baker et al., 2011).

Lastly, despite the finding that parents' deployment experiences had no interaction with parents' gender when testing their contribution to emotion socialization, and there was no significant difference between civilian mothers and deployed mothers regarding their emotion socialization, overall deployed mothers were relatively small in number and most fathers were deployed in the sample. Furthermore, there was a lack of information about military service (length, overseas versus local, etc.). Consequently, it is difficult to conclude that deployment experiences have no effect on parents' emotion socialization. Future studies should include characteristics of military service to examine what aspects of deployment have an effect on parental emotion socialization and its association with child outcomes.

Acknowledgment: The study reported in this article was supported by Grant R01DA030114 from the Division of Epidemiology, Services, and Prevention Research of the National Institute on Drug Abuse in the United States, to Abigail $\mathrm{H}$. Gewirtz, Ph.D.

\section{References}

Albrecht, T. L., Burleson, B. R., \& Goldsmith, D. (1994). Supportive communication. In M. L., Knapp \& G. R. Miller (Eds.), Handbook of interpersonal communication $\left(2^{\text {nd }}\right.$ ed., pp. 419-449). Thousand Oaks, CA: Sage.

Baker, J. K., Fenning, R. M., \& Crnic, K. A. (2011). Emotion socialization by mothers and fathers: Coherence among behaviors and associations with parent attitudes and children's social competence. Social Development, 20(2), 412-430.

Belsky, J., Fish, M., \& Isabella, R. (1991). Continuity and discontinuity in infant negative and positive emotionality: Family antecedents and attachment consequences. Developmental Psychology, 23(3), 421-431.

Belsky, J., Hsieh, K. H., \& Crnic, K. (1998).
Mothering, fathering, and infant negativity as antecedents of boys' externalizing problems and inhibition at age 3 years: Differential susceptibility to rearing experience? Development and Psychopathology, 10(2), 301-319.

Birnbaum, D. W., \& Croll, W. L. (1984). The etiology of children's stereotypes about sex differences in emotionality. Sex Roles, 10(910), 677-691.

Chandra, A., Lara-Cinisomo, S., Jaycox, L. H., Tanielian, T., Burns, R. M., Ruder, T., \& Han, B. (2010). Children on the homefront: The experience of children from military families. Pediatrics, 125(1), 16-25.

Chartrand, M. M., Frank, D. A., White, L. F., \& Shope, T. R. (2008). Effect of parents' wartime deployment on the behavior of young children in military families. Archives of Pediatrics \& Adolescent Medicine, 162(11), 1009-1014.

Denham, S. A., Mitchell-Copeland, J., Strandberg, K., Auerbach, S., \& Blair, K. (1997). Parental contributions to preschoolers' emotional competence: Direct and indirect effects. Motivation and Emotion, 21(1), 65-86.

Diener, E., Larsen, R. J., Levine, S., \& Emmons, R. A. (1985). Intensity and frequency: Dimensions underlying positive and negative affect. Journal of Personality and Social Psychology, 48(5), 1253.

Eisenberg, N., Cumberland, A., \& Spinrad, T. L. (1998). Parental socialization of emotion. Psychological Inquiry, 9(4), 241-273.

Eisenberg, N., Cumberland, A., Spinrad, T. L., Fabes, R. A., Shepard, S. A., Reiser, M., Murphy, L., \& Guthrie, I. K. (2001). The relations of regulation and emotionality to children's externalizing and internalizing problem behavior. Child Development, 72(4), 1112-1134.

Eisenberg, N., Fabes, R. A., Bernzweig, J., Karbon, M., Poulin, R., \& Hanish, L. (1993). The relations of emotionality and regulation to preschoolers' social skills and sociometric status. Child Development, 64(5), 1418-1438.

Eisenberg, N., \& Fabes, R. A. (1994). Mothers' reactions to children's negative emotions: 
Relations to children's temperament and anger behavior. Merrill-Palmer Quarterly, 40, 138156.

Eisenberg, N., Fabes, R. A., Murphy, B., Maszk, P., Smith, M., \& Karbon, M. (1995). The role of emotionality and regulation in children's social functioning: A longitudinal study. Child Development, 66(5), 1360-1384.

Eisenberg, N., Fabes, R. A., \& Murphy, B. C. (1996). Parents' reactions to children's negative emotions: Relations to children's social competence and comforting behavior. Child Development, 67(5), 2227-2247.

Eisenberg, N., Fabes, R. A., Shepard, S. A., Guthrie, I. K., Murphy, B. C., \& Reiser, M. (1999). Parental reactions to children's negative emotions: Longitudinal relations to quality of children's social functioning. Child Development, 70(2), 513-534.

Eisenberg, N., Wentzel, N., \& Harris, J. D. (1998). The Role of emotionality and regulation in empathy-related responding. School Psychology Review, 27(4), 506-521.

Engle, J. M., \& McElwain, N. L. (2011). Parental reactions to toddlers' negative emotions and child negative emotionality as correlates of problem behavior at the age of three. Social Development, 20(2), 251-271.

Fabes, R. A., Eisenberg, N., \& Bernzweig, J. (1990). The coping with children's negative emotions scale: Procedures and scoring. Unpublished document available from the authors, Arizona State University, Tempe, AZ. Retrieved April 1, 2003 from http://www. public.asu.edu/ sparky00/fabes/cnesall.pdf

Fabes, R. A., Leonard, S. A., Kupanoff, K., \& Martin, C. L. (2001). Parental coping with children's negative emotions: Relations with children's emotional and social responding. Child Development, 72(3), 907-920.

Fabes, R. A., Poulin, R. E., Eisenberg, N., \& Madden-Derdich, D. A. (2002). The Coping with Children's Negative Emotions Scale (CCNES): Psychometric properties and relations with children's emotional competence. Marriage \& Family Review, 34(3), 285-310.

Fivush, R., Brotman, M. A., Buckner, J. P., \& Goodman, S. H. (2000). Gender differences in parent-child emotion narratives. Sex Roles, 42(3-4), 233-253.

Fox, N. A., \& Calkins, S. D. (2003). The development of self-control of emotion: Intrinsic and extrinsic influences. Motivation and Emotion, 27(1), 7-26.

Garside, R. B., \& Klimes-Dougan, B. (2002). Socialization of discrete negative emotions: Gender differences and links with psychological distress. Sex Roles, 47(3-4), 115-128.

Gewirtz, A., \& Davis, L. (2014). Parenting practices and emotion regulation in National Guard and Reserve families: Early findings from the After Deployment Adaptive Parenting Tools/ADAPT study. In S. M. Wadsworth \& D. S. Riggs (Eds.), Military deployment and its consequences for families (pp.111-131). New York: Springer.

Gorman, G. H., Eide, M., \& Hisle-Gorman, E. (2010). Wartime military deployment and increased pediatric mental and behavioral health complaints. Pediatrics, 126(6), 10581066.

Gottman, J. M., Katz, L. F., \& Hooven, C. (1996). Parental meta-emotion philosophy and the emotional life of families: Theoretical models and preliminary data. Journal of Family Psychology, 10(3), 243.

Gottman, J. M., Katz, L. F., \& Hooven, C. (1997). Meta-emotion: How families communicate emotionally. Mahwah, NJ: Lawrence Erlbaum.

Hastings, P. D., Rubin, K. H., \& DeRose, L. (2005). Links among gender, inhibition, and parental socialization in the development of prosocial behavior. Merrill-Palmer Quarterly (1982-), 51(4), 467-493.

Hastings, P. D., \& De, I. (2008). Parasympathetic regulation and parental socialization of emotion: Biopsychosocial processes of adjustment in preschoolers. Social Development, 17(2), 211-238.

Hosek, J., Kavanagh, J. E., \& Miller, L. L. (2006). How deployments affect service members. Santa Monica, CA: The RAND Corporation.

Keltner, D., Moffitt, T. E., \& Stouthamer-Loeber, 
M. (1995). Facial expressions of emotion and psychopathology in adolescent boys. Journal of Abnormal Psychology, 104(4), 644.

Larsen, R. J., \& Diener, E. (1987). Affect intensity as an individual difference characteristic: A review. Journal of Research in Personality, 21(1), 1-39.

Lengua, L. J. (2003). Associations among emotionality, self-regulation, adjustment problems, and positive adjustment in middle childhood. Journal of Applied Developmental Psychology, 24(5), 595-618.

Little, R. J., \& Rubin, D. B. (1989). The analysis of social science data with missing values. Sociological Methods \& Research, 18(2-3), 292-326.

MacDermid, S. M. (2006, June 22). Multiple transitions of deployment and reunion for military families. Purdue University. Retrieved from http://www.networkofcare. org/library/DeployReunionPPTPurdue.pdf

McElwain, N. L., Halberstadt, A. G., \& Volling, B. L. (2007). Mother- and father-reported reactions to children's negative emotions: Relations to young children's emotional understanding and friendship quality. Child Development, 78(5), 1407-1425.

Oldehinkel, A. J., Hartman, C. A., De Winter, A. F., Veenstra, R., \& Ormel, J. (2004). Temperament profiles associated with internalizing and externalizing problems in preadolescence. Development and Psychopathology, 16(2), 421-440.

Oldehinkel, A. J., Hartman, C. A., Ferdinand, R. F., Verhulst, F. C., \& Ormel, J. (2007). Effortful control as modifier of the association between negative emotionality and adolescents' mental health problems. Development and Psychopathology, 19(2), 523-539.

O’Neal, C. R., \& Magai, C. (2005). Do parents respond in different ways when children feel different emotions? The emotional context of parenting. Development and Psychopathology, 17(2), 467-487.

Parke, R. D. (1995). Fathers and families. In M. H. Bornstein (Ed.), Handbook of parenting: Vol. 3. Status and social conditions of parenting (pp.27-63). Hillsdale, NJ: Lawrence Erlbaum Associates.

Paulussen-Hoogeboom, M. C., Stams, G. J. J., Hermanns, J., \& Peetsma, T. T. (2007). Child negative emotionality and parenting from infancy to preschool: A meta-analytic review. Developmental Psychology, 43(2), 438.

Price, J. L., Monson, C. M., Callahan, K., \& Rodriguez, B. F. (2006). The role of emotional functioning in military-related PTSD and its treatment. Journal of Anxiety Disorders, 20(5), 661-674.

Propper, C., \& Moore, G. A. (2006). The influence of parenting on infant emotionality: A multi-level psychobiological perspective. Developmental Review, 26(4), 427-460.

Reynolds, C. R., \& Kamphaus, R. W. (1998). BASC: Behavior assessment system for children: Manual. Circle Pines, MN: American Guidance Service, Inc.

Rothbart M. K., \& Bates J. E. (2006). Temperament. In W. Damon, R. Lerner, \& N. Eisenberg (Eds.), Handbook of child psychology: Vol. 3. Social, emotional, and personality development (6th ed., pp.99-166). New York: Wiley.

Rothbart, M. K., Ahadi, S. A., Hershey, K. L., \& Fisher, P. (2001). Investigations of temperament at three to seven years: The Children's Behavior Questionnaire. Child Development, 72(5), 1394-1408.

Rydell, A. M., Berlin, L., \& Bohlin, G. (2003). Emotionality, emotion regulation, and adaptation among 5-to 8-year-old children. Emotion, 3(1), 30.

Sallquist, J. V., Eisenberg, N., Spinrad, T. L., Reiser, M., Hofer, C., Zhou, Q., \& Eggum, N. (2009). Positive and negative emotionality: trajectories across six years and relations with social competence. Emotion, 9(1), 15.

Sanson, A., Hemphill, S. A., \& Smart, D. (2004). Connections between temperament and social development: A review. Social Development, 13(1), 142-170.

Silk, J. S., Shaw, D. S., Prout, J. T., O'Rourke, F., Lane, T. J., \& Kovacs, M. (2011). Socialization of emotion and offspring internalizing symptoms in mothers with 
childhood-onset depression. Journal of Applied Developmental Psychology, 32(3), 127-136.

Spinrad, T. L., Eisenberg, N., Gaertner, B., Popp, T., Smith, C. L., Kupfer, A., Greving, K., Liew, J., \& Hofer, C. (2007). Relations of maternal socialization and toddlers' effortful control to children's adjustment and social competence. Developmental Psychology, 43(5), 1170.

Suveg, C., Zeman, J., Flannery-Schroeder, E., \& Cassano, M. (2005). Emotion socialization in families of children with an anxiety disorder. Journal of Abnormal Child Psychology, 33(2), 145-155.

Toth, S. L., \& Cicchetti, D. (1996). Patterns of relatedness, depressive symptomatology, and perceived competence in maltreated children. Journal of Consulting and Clinical Psychology, 64(1), 32.
Zahn-Waxler, C., Klimes-Dougan, B., \& Slattery, M. (2000). Internalizing disorders of childhood and adolescence: Progress and prospects for advances in understanding anxiety and depression. Development and Psychopathology, 12, 443-466.

Zeanah, C. H., \& Fox, N. A. (2004). Temperament and attachment disorders. Journal of Clinical Child and Adolescent Psychology, 33(1), 32-41.

Received February 15, 2015

Revision Received February 24, 2015

Accepted February 25, 2015 